\title{
Sarpogrelate Dilates Cerebral Arteries in the Absence of Exogenous Serotonin
}

\author{
Maiko KAWAMURA,, ${ }^{1,2}$ Masanori ISHIGURO, ${ }^{2}$ \\ Takashi NAGAMINE, ${ }^{2}$ and Kiyohiro HOUKIN ${ }^{1,3}$
Departments of ${ }^{1}$ Neurosurgery and ${ }^{2}$ Systems Neuroscience, School of Medicine, Sapporo Medical University, Sapporo, Hokkaido; ${ }^{3}$ Department of Neurosurgery, Hokkaido University, Sapporo, Hokkaido

\begin{abstract}
Vasoconstriction of arteries induced by serotonin (5-hydroxytryptamine: $5-\mathrm{HT}$ ) is mediated by 5 -HT $\mathrm{T}_{2 \mathrm{~A}}$ and $5-\mathrm{HT}_{1 \mathrm{~B}}$ receptors localized on smooth muscle. The present study investigated the impact of sarpogrelate, a 5-HT $\mathrm{T}_{2 \mathrm{~A}}$ receptor antagonist, on cerebral artery diameter in the presence and absence of exogenous 5-HT. Diameter measurements were obtained in vitro from rabbit cerebral arteries pressurized to $60 \mathrm{mmHg}$. In the absence of 5-HT, arteries exhibiting pressure-induced myogenic tone dilated to sarpogrelate in a concentration-dependent manner (half maximal inhibitory concentration $\left[\mathrm{IC}_{50}\right] \approx 2.3$ $\mu \mathrm{M})$. In a separate experimental series, exogenous application of 5-HT $(0.01 \mu \mathrm{M})$ caused further constriction of myogenically active arteries, decreasing cerebral artery diameter by an additional $25 \%$. In the presence of $5-\mathrm{HT}$, sarpogrelate caused concentration-dependent vasodilation (IC $\left.{ }_{50} \approx 2.3 \mu \mathrm{M}\right)$ that was similar to that observed in the absence of exogenous 5-HT. Dilation induced by sarpogrelate was not affected by physical removal of the endothelium or inhibition of nitric oxide synthase with $\mathrm{N} \omega$-nitro L-arginine. The highest concentration of sarpogrelate $(100 \mu \mathrm{M})$ induced near maximal dilation, comparable to dilation induced by the L-type voltage-dependent calcium channel antagonist diltiazem. These findings suggest that in rabbit cerebral arteries, sarpogrelate has direct vasodilator effects on vascular smooth muscle.
\end{abstract}

Key words: 5-hydroxytryptamine, cerebral artery, sarpogrelate, vascular smooth muscle, serotonin

\section{Introduction}

Receptors for serotonin (5-hydroxytryptamine: 5-HT) have been classified into seven subtypes, 5$\mathrm{HT}_{1-7}$, and 15 distinct receptor isoforms have been identified.7) Activations of $5-\mathrm{HT}_{1 \mathrm{~B}}$ and $5-\mathrm{HT}_{2 \mathrm{~A}}$ receptor subtypes are thought to underlie vascular diameter changes induced by $5-\mathrm{HT}$ in animals and humans. ${ }^{29)}$ Studies using a variety of species, including rats, dogs, and pigs, have demonstrated that 5HT-induced vasoconstriction is mediated through stimulation of smooth muscle $5-\mathrm{HT}_{2 \mathrm{~A}}$ receptors whereas vasodilation occurs via stimulation of 5$\mathrm{HT}_{1 \mathrm{~B}}$ receptors located in vascular endothelium. ${ }^{1,4,7)}$

Ketanserin, classified as an antihypertensive agent by the World Health Organization ${ }^{32)}$ was originally thought to be a selective $5-\mathrm{HT}_{2 \mathrm{~A}}$ receptor antagonist. However, ketanserin is now known to also exhibit significant antagonism of $\alpha_{1}$-adrenoceptors ${ }^{17)}$

Received March 15, 2012; Accepted July 30, 2012 and histamine $\mathrm{H}_{1}$ receptors. ${ }^{10)}$ Sarpogrelate is a newly developed $5-\mathrm{HT}_{2 \mathrm{~A}}$ receptor antagonist that, unlike ketanserin, has little effect on $\alpha_{1}$-adrenoceptors. ${ }^{17)}$ Sarpogrelate has been shown to selectively inhibit $5-\mathrm{HT}_{2 \mathrm{~A}}$ receptors located on rabbit platelets, rat brain, and caudal arteries. ${ }^{16,20,28)}$ Sarpogrelate is clinically important because it blocks serotonininduced platelet aggregation and has applications in the treatment of arteriosclerosis ${ }^{6)}$ including diabetes mellitus, ${ }^{18,21)}$ Buerger's disease, ${ }^{24)}$ Raynaud's disease, ${ }^{9)}$ and coronary artery disease. ${ }^{13,25)}$ However, the actions of sarpogrelate on the cerebral vascular system have not been studied.

The present study examined responses to sarpogrelate in rabbit cerebral arteries exhibiting stable pressure-induced myogenic tone, and found that sarpogrelate caused significant concentration-dependent dilation in the absence of exogenous 5-HT. Our findings suggest that in addition to antagonism of $5-\mathrm{HT}_{2 \mathrm{~A}}$ receptors, sarpogrelate can induce cerebral artery dilation through a direct effect on smooth 
muscle voltage-dependent $\mathrm{Ca}^{2+}$ channels.

\section{Materials and Methods}

New Zealand White rabbits (male, 2.0-3.0 kg) were used in this study. Rabbits were euthanized (pentobarbital $150 \mathrm{mg} / \mathrm{kg}$, intravenous), then decapitated. Brains were then removed and immersed in a dissection dish filled with cold $\left(4^{\circ} \mathrm{C}\right)$, oxygenated $\left(20 \% \mathrm{O}_{2}\right.$, $5 \% \mathrm{CO}_{2}, 75 \% \mathrm{~N}_{2}$ ) physiological saline solution (PSS) of the following composition (in $\mathrm{mM}$ ); $118.5 \mathrm{NaCl}$, $4.7 \mathrm{KCl}, 24 \mathrm{NaHCO}_{3}, 1.18 \mathrm{KH}_{2} \mathrm{PO}_{4}, 2.5 \mathrm{CaCl}_{2}, 1.2$ $\mathrm{MgCl}_{2}, 0.023$ ethylenediaminetetraacetic acid, and 11 glucose. Cerebral artery segments obtained from branches of cerebellar or posterior cerebral arteries (100-300 $\mu \mathrm{m}$ in diameter) were carefully dissected from the brain and cleaned of blood using a stereodissection microscope. Experimental protocols (\#08-109) were approved by the Institution Animal Care and Use Committee of Sapporo Medical University.

Arteries were cannulated on glass pipettes mounted in a $5 \mathrm{ml}$ myograph chamber (Living Systems Instruments, Burlington, Vermont, USA), superfused with PSS (pH 7.4) aerated with $20 \% \mathrm{O}_{2}, 5 \%$ $\mathrm{CO}_{2}$, and $75 \% \mathrm{~N}_{2}$ and warmed to $37^{\circ} \mathrm{C}$. Arterial diameter was measured using video edge detection equipment and recorded using data acquisition software (Lab-Trax ${ }^{\circledR}$ with Data-Trax ${ }^{\circledR}$ recording software; World Precision Instruments, Sarasota, Florida, USA). Artery viability was tested at the start of each experiment by exposing the arteries to 60 $\mathrm{mM}$ extracellular $\mathrm{K}^{+}$. Arteries were discarded if the constriction induced by $60 \mathrm{mM} \mathrm{K}^{+}$was less than a $50 \%$ decrease in diameter.

After an equilibration period of 30 minutes at 20 $\mathrm{mmHg}$, intraluminal pressure was elevated to 60 mmHg. Once myogenic tone developed and stabilized, sarpogrelate at concentrations varying from 0.001 to $100 \mu \mathrm{M}$ were administered in the presence and absence of 5-HT. Some arteries were denuded of vascular endothelium by placing an air bubble in the lumen for 1 minute, followed by luminal washing with distilled water for 30 seconds. Endothelial disruption was verified by the absence of dilator response to acetylcholine $(1 \mu \mathrm{M}$ and $100 \mu \mathrm{M})$ after myogenic tone had developed. To examine the impact of sarpogrelate on nitric oxide production, studies were also performed in the presence and absence of $\mathrm{N} \omega$-nitro-L-arginine (LNNA, $100 \mu \mathrm{M}$ ), a nitric oxide synthase inhibitor. At the end of each experiment, the passive (fully dilated) diameter was obtained with $50 \mu \mathrm{M}$ diltiazem in $\mathrm{Ca}^{2+}$-free PSS.

Results are expressed as mean \pm standard error of the mean. ORIGIN ${ }^{\circledR}$ (version 7.5; OriginLab Cor- poration, Northampton, Massachusetts, USA) and SPSS (SPSS Japan Inc., Tokyo) were used for statistical analysis. Statistical significance was considered at the level of $p<0.05$ or $p<0.01$ using either Student's $t$ test or repeated measures analysis of variance.

Sarpogrelate was obtained from Tanabe-Mitsubishi Chemical Corporation, Tokyo. Sodium pentobarbital was obtained from Tokyo Chemical Industry Corporation, Tokyo. All other drugs were obtained from Sigma (St Louis, Missouri, USA).

\section{Results}

Initial studies were designed to examine the impact of sarpogrelate on pressure-induced constriction of rabbit cerebral arteries in the absence of exogenous 5-HT. Sarpogrelate $(0.01 \mu \mathrm{M}$ to $100 \mu \mathrm{M})$ caused concentration-dependent vasodilation (half maximal inhibitory concentration $\left(\mathrm{IC}_{50}\right)$ value of sarpogrelate $2.30 \mu \mathrm{M}$ ) of isolated cerebral arteries pressurized to $60 \mathrm{mmHg}(\mathrm{n}=5)$ (Fig. 1A). The highest concentration of sarpogrelate $(100 \mu \mathrm{M})$ caused near maximal dilation of arteries, to $97.0 \pm 0.1 \%$ of their passive diameter (Fig. 1C). In a separate experimental series, pressurized cerebral arteries exhibiting myogenic tone were treated with 5 -HT $(0.01 \mu \mathrm{M})$ prior to the addition of sarpogrelate. At $60 \mathrm{mmHg}, 5-\mathrm{HT}$ exposure resulted in additional constriction representing a further decrease in diameter of $24.6 \pm 3.6 \%$ (Fig. 1B). In the presence of 5-HT, sarpogrelate also caused concentration-dependent vasodilation with an $\mathrm{IC}_{50}$ value of $2.06 \mu \mathrm{M}$. Near maximum vasodilation was again observed with $100 \mu \mathrm{M}$ sarpogrelate (Fig. 1D). These data demonstrate that sarpogrelate caused similar concentration-dependent dilation of myogenically active cerebral arteries in the absence and presence of 5-HT.

To examine the role of the vascular endothelium in sarpogrelate-induced vasodilation, responses were examined in endothelial-denuded cerebral arteries. Endothelium removal was confirmed by the absence of dilation induced by acetylcholine (Ach, 1 $\mu \mathrm{M}$ or $100 \mu \mathrm{M}$ ). The diameter of endothelial-denuded arteries was $119.3 \pm 8.8 \mu \mathrm{m}$ prior to Ach administration, and was $123.8 \pm 8.1 \mu \mathrm{m}$ and $118.9 \pm$ $9.4 \mu \mathrm{m}$ in the presence of $1 \mu \mathrm{M}$ and $100 \mu \mathrm{M}$ Ach, respectively. Sarpogrelate-induced ( $1 \mu \mathrm{M}$ and $100 \mu \mathrm{M})$ vasodilation of endothelium-denuded vessels was comparable to responses in endothelial intact arteries (Fig. 2). These data indicate that sarpogrelate causes vasodilation via a direct effect on the vascular smooth muscle cells within the arterial wall.

To examine the potential involvement of enhanced nitric oxide production in sarpogrelate-in- 

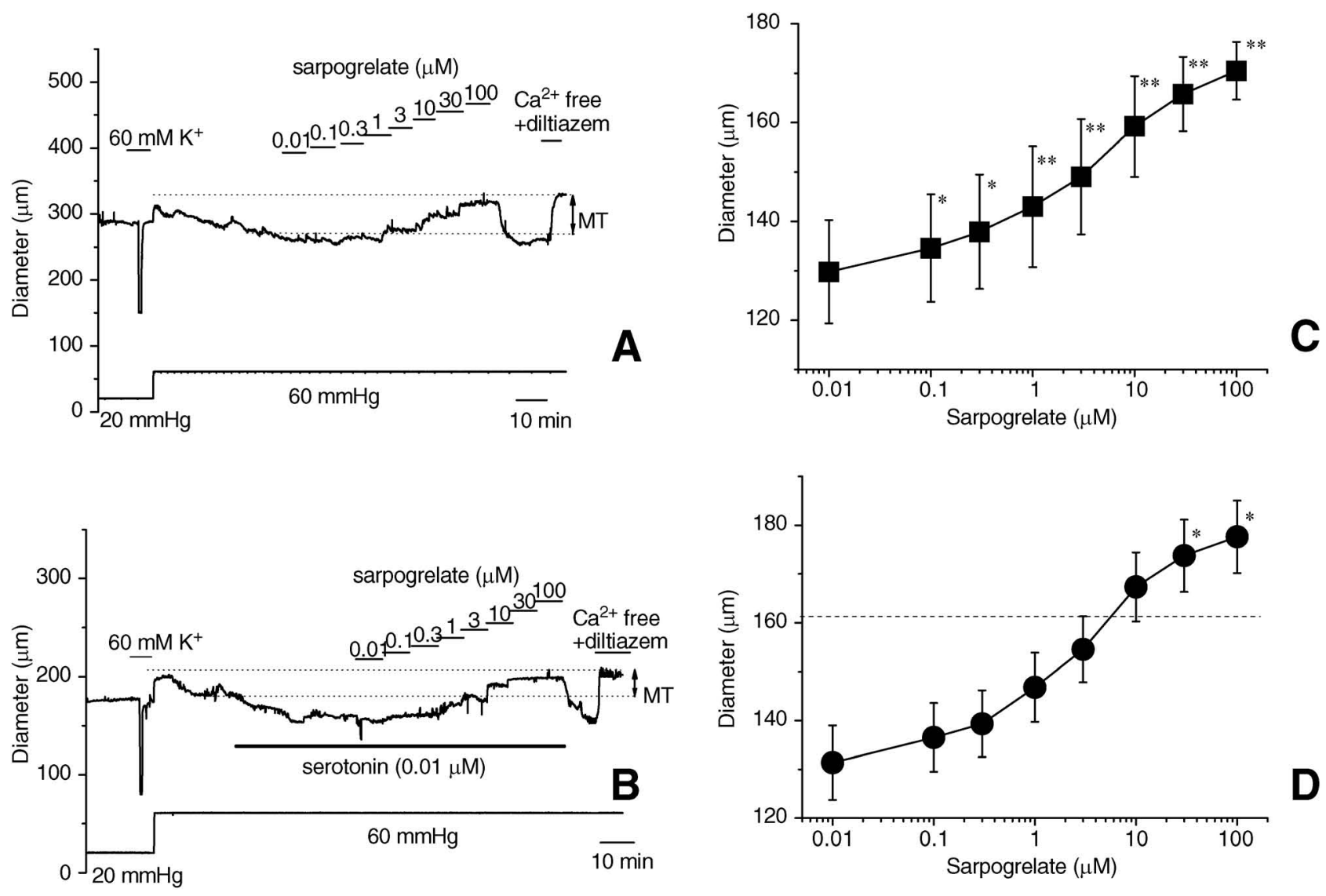

Fig. 1 A, B: Representative experiments showing the effect of sarpogrelate on arterial diameter in the absence (A) and presence (B) of 0.01 $\mu \mathrm{M}$ 5-hydroxytryptamine (5-HT). MT: myogenic tone. C, D: Effects of increasing concentrations of sarpogrelate on luminal diameter of rabbit cerebral arteries at $60 \mathrm{mmHg}$. Sarpogrelate caused concentrationdependent dilation of cerebral arteries in physiological saline solution in the absence of 5-HT (C). Sarpogrelate caused concentration-dependent dilation of cerebral arteries in physiological saline solution containing 5-HT (D). $\quad{ }^{*} p<$ $0.05,{ }^{* *} p<0.01$. Dotted line in $\mathrm{D}$ indicates mean diameter in the absence of $5-\mathrm{HT}$.

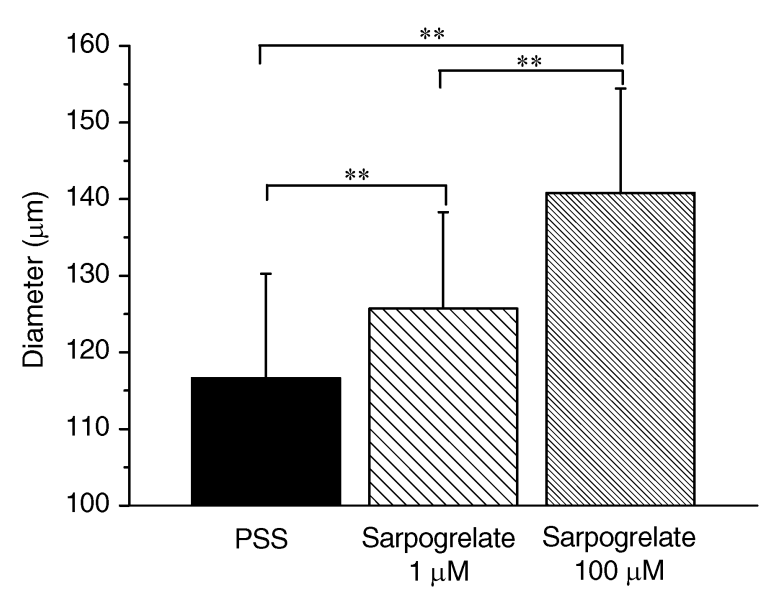

Fig. 2 Effect of sarpogrelate on endothelium-denuded arteries. Sarpogrelate $(1 \mu \mathrm{M}$ and $100 \mu \mathrm{M})$ significantly dilated pressure-induced constriction of cerebral arteries denuded of vascular endothelium $\left({ }^{* *} p<0.01\right)$. PSS: physiological saline solution. duced vasodilation, studies were performed using the inhibitor of nitric oxide synthase, LNNA $(100$ $\mu \mathrm{M})$. Sarpogrelate significantly dilated endothelial intact arteries from a mean diameter of $171.5 \pm 10.4$ $\mu \mathrm{m}$ to a mean diameter of $185.0 \pm 14.1 \mu \mathrm{m}$. Subsequent addition of LNNA did not alter the diameter $(185.4 \pm 13.9 \mu \mathrm{m})$ (Fig. 3A). Further, pre-treatment of an additional set of endothelial intact arteries with LNNA did not alter sarpogrelate-induced dilation (Fig. 3B). These data demonstrate that sarpogrelate dilated cerebral arteries in a manner independent of nitric oxide generation.

Cerebral artery dilation induced by $100 \mu \mathrm{M}$ sarpogrelate was similar in magnitude to dilation caused by the removal of extracellular $\mathrm{Ca}^{2+}$ from the PSS. Furthermore, dilation induced by sarpogrelate and $\mathrm{Ca}^{2+}$-free PSS were not additive (Fig. 4), suggesting that sarpogrelate may impair the influx of $\mathrm{Ca}^{2+}$ into cerebral artery myocytes. Considering that voltage-dependent $\mathrm{Ca}^{2+}$ channels (VDCCs) represent 



Fig. 3 Summary of the diameter measurements of rabbit cerebral arteries in the presence of sarpogrelate (100 $\mu \mathrm{M}$ ) and $\mathrm{N} \omega$-nitro-L-arginine (LNNA, $100 \mu \mathrm{M}$ ), an inhibitor of nitric oxide synthesis. A: Sarpogrelate dilated arteries from $171.5 \pm 10.4$ to $185.0 \pm 14.1 \mu \mathrm{m}$, and the diameter was similar after addition of LNNA (185.4 \pm $13.9 \mu \mathrm{m})(\mathrm{n}=6)$. B: LNNA did not change the diameter $(149.9 \pm 8.5$ to $149.6 \pm 8.6 \mu \mathrm{m})$ or affect sarpogrelate-induced vasodilation $(179.4 \pm 9.2 \mu \mathrm{m}) \quad(\mathrm{n}=6) .{ }^{*} \mathrm{p}<$ $\mathbf{0 . 0 5},{ }^{* *} \mathbf{p}<\mathbf{0 . 0 1}$. NS: not significant, PSS: physiological saline solution.

the major $\mathrm{Ca}^{2+}$ influx pathway in these cells, comparisons were made between the actions of sarpogrelate and the VDCC inhibitor diltiazem. In a manner similar to the removal of extracellular $\mathrm{Ca}^{2+}$, dilations to maximal concentrations of sarpogrelate $(100 \mu \mathrm{M})$ and diltiazem $(50 \mu \mathrm{M})$ were not additive (Fig. 5). The effect of a lower concentration of sarpogrelate $(1 \mu \mathrm{M})$ was also studied on cerebral artery dilation induced by three distinct classes of VDCC inhibitors: benzothiazepine diltiazem, phenylalkylamine verapamil, and dihydropyridine nifedipine. Sarpogrelate caused a leftward shift of concentration-response curve of all three VDCC inhibitors. $\mathrm{IC}_{50}$ values changed from $1.8 \pm 0.4$ to $0.6 \pm 0.2 \mu \mathrm{M}$ with diltiazem, from $1.6 \pm 0.6$ to $0.4 \pm 0.2 \mu \mathrm{M}$ with
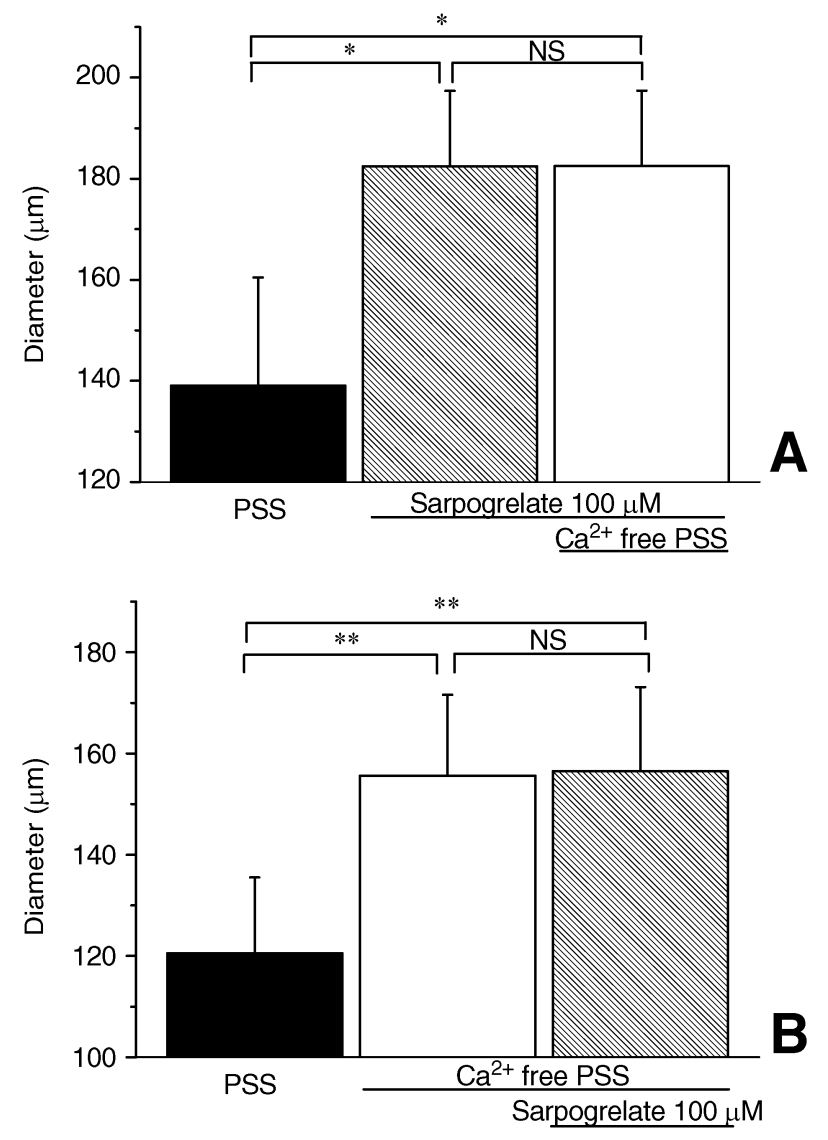

Fig. 4 Summary of the diameter of rabbit cerebral arteries in the presence of sarpogrelate and calcium-free physiological saline solution (PSS). A: Sarpogrelate dilated arteries from 139.1 \pm 21.4 to $182.4 \pm 12.9 \mu \mathrm{m}$, and the diameter was similar after addition of calcium free PSS $(182.5 \pm 14.9 \mu \mathrm{m})(\mathrm{n}=5)$. B: Calcium-free PSS dilated arteries from $120.6 \pm 15.0$ to $155.6 \pm 16.0 \mu \mathrm{m}$, and the diameter was similar after subsequent addition of sarpogrelate $(156.6 \pm 16.7 \mu \mathrm{m})(\mathrm{n}=6) .{ }^{*} \mathbf{p}<0.05,{ }^{* *} \mathbf{p}$ $<$ 0.01. NS: not significant.

verapamil, and from $0.4 \pm 0.1$ to $0.2 \pm 0.1 \mu \mathrm{M}$ with nifedipine (Fig. 6). These data suggest that sarpogrelate may act through inhibition of VDCCs to reverse pressure-induced constriction of rabbit cerebral arteries.

\section{Discussion}

This study provides evidence indicating that the purported 5- $\mathrm{HT}_{2 \mathrm{~A}}$ receptor antagonist sarpogrelate can dilate rabbit cerebral arteries via a mechanism independent of $5-\mathrm{HT}_{2 \mathrm{~A}}$ receptors. Specifically, we observed that: In the absence of $5-\mathrm{HT}$, sarpogrelate dilated cerebral arteries exhibited pressure-induced myogenic tone; the efficacy of sarpogrelate to induce cerebral artery vasodilation was similar in the 

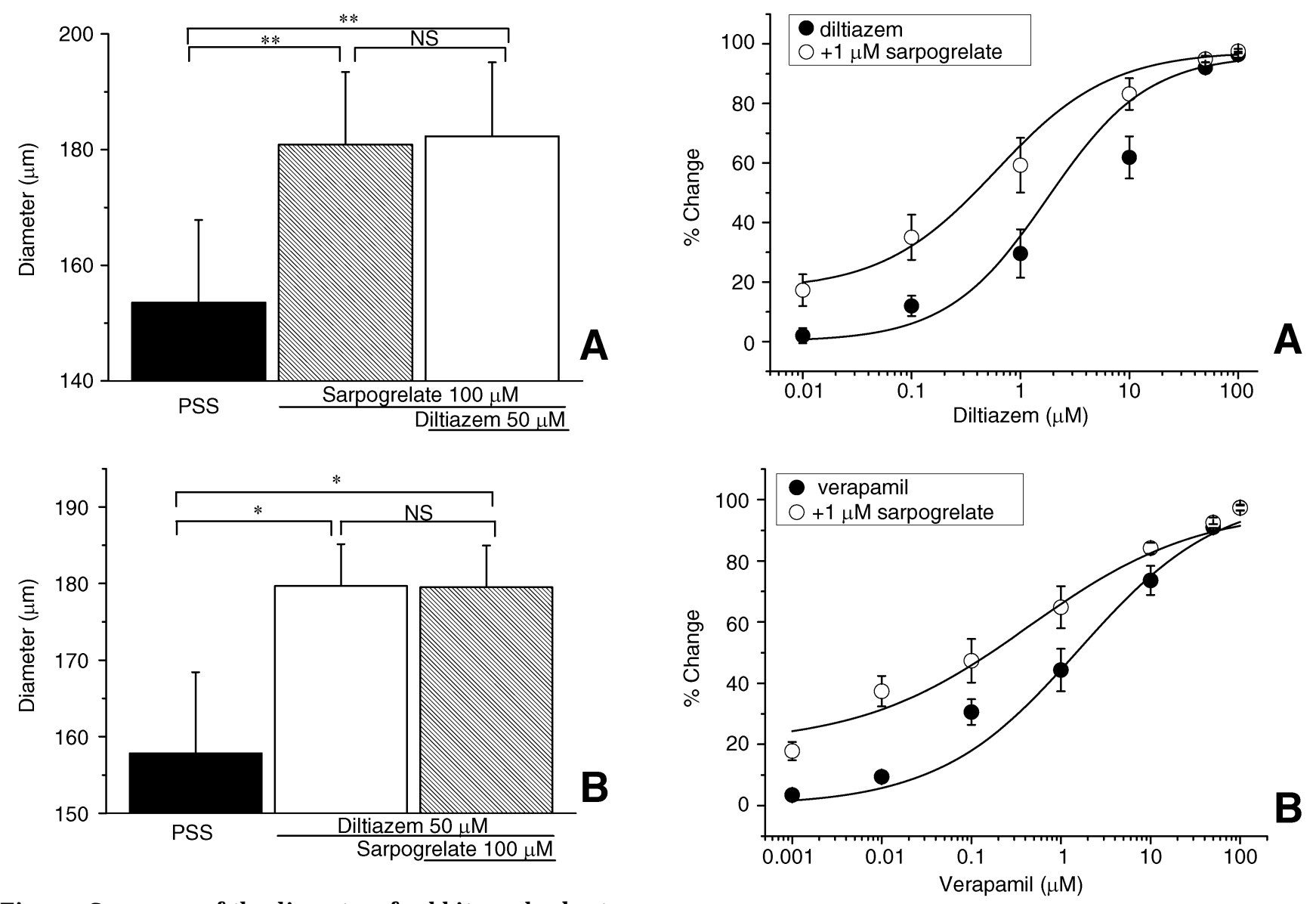

Fig. 5 Summary of the diameter of rabbit cerebral arteries in the presence of sarpogrelate and diltiazem. A: Sarpogrelate dilated arteries from $153.5 \pm 14.3$ to 180.9 $\pm 12.6 \mu \mathrm{m}$, and the diameter was similar after addition of diltiazem (182.3 $\pm 12.9 \mu \mathrm{m})$. B: Diltiazem dilated arteries from $157.8 \pm 10.6$ to $179.7 \pm 5.5 \mu \mathrm{m}$, and the diameter was similar after addition of sarpogrelate (179.5 $\pm 5.5 \mu \mathrm{m}) . \quad{ }^{*} \mathbf{p}<\mathbf{0 . 0 5},{ }^{* *} \mathbf{p}<\mathbf{0 . 0 1}$. NS: not significant, PSS: physiological saline solution.

presence and absence of exogenous 5-HT; sarpogrelate exhibited direct vasodilator effects on cerebral artery smooth muscle independent of nitric oxide and vascular endothelium; and maximal dilations to sarpogrelate and VDCC inhibitors were not additive and sarpogrelate caused a leftward shift in the $\mathrm{IC}_{50}$ curves of three types of calcium antagonists without changing maximum arterial dilation. In summary, these findings demonstrate that sarpogrelate can dilate cerebral arteries through a mechanism independent of antagonism of $5-\mathrm{HT}_{2 \mathrm{~A}}$ receptors.

5 -HT is a powerful vasomotor agent causing increased cytoplasmic calcium levels in the cerebral artery myocytes assessed by radioactive ${ }^{45} \mathrm{Ca}$ influx and efflux measurements. ${ }^{31)}$ Among the various 5 -HT receptor subtypes, $5-\mathrm{HT}_{2 \mathrm{~A}}$ receptor has been

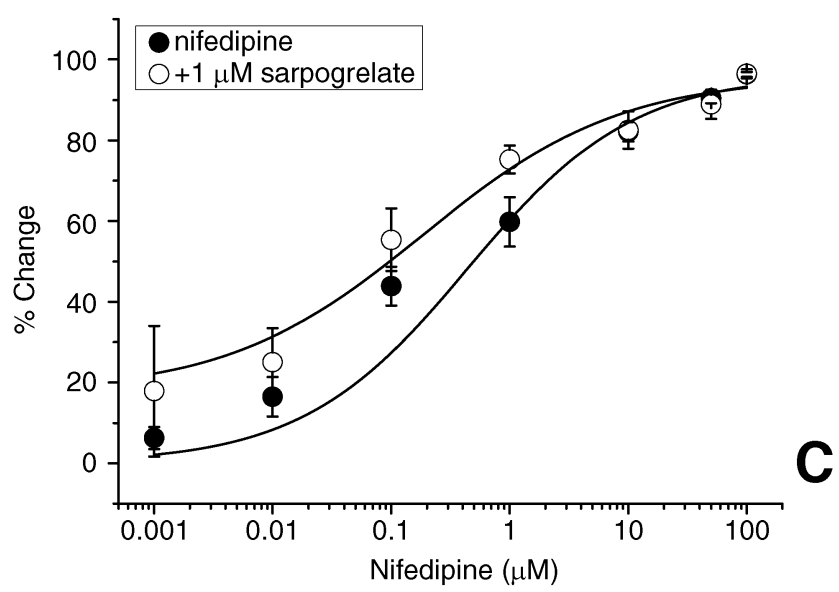

Fig. 6 Effect of sarpogrelate $(1 \mu \mathrm{M})$ on calcium channel blocker-induced (diltiazem, verapamil, and nifedipine) vasodilation in rabbit cerebral arteries. A: Doseresponse curves of diltiazem $(n=9)$. Half maximal inhibitory concentration $\left(\mathrm{IC}_{50}\right)$ of diltiazem changed from $1.8 \pm 0.4$ to $0.6 \pm 0.2 \mu \mathrm{M}$ after addition of sarpogrelate. B: Dose-response curves of verapamil $(n=8)$. IC $_{50}$ of verapamil changed from $1.6 \pm 0.6$ to $0.4 \pm 0.2 \mu \mathrm{M}$ after addition of sarpogrelate. C: Dose-response curves of nifedipine $(\mathrm{n}=9)$ ). $\mathrm{IC}_{50}$ of nifedipine changed from 0.4 \pm 0.1 to $0.2 \pm 0.1 \mu \mathrm{M}$ after addition of sarpogrelate. 
implicated in a variety of cellular processes such as vascular smooth muscle contraction, ${ }^{2)}$ non-vascular smooth muscle contraction (including uterine contraction), ${ }^{8)}$ and platelet aggregation. ${ }^{15)}$ Sarpogrelate has been reported to be a specific antagonist of the $5-\mathrm{HT}_{2 \mathrm{~A}}$ receptor, that unlike ketanserin, has no inhibitory effect on $\alpha_{1}$-adrenoceptors. ${ }^{3)}$ Our in vitro data demonstrate that $10 \mu \mathrm{M}$ sarpogrelate abolished 5-HT-induced cerebral artery constriction, which is consistent with a previous study of the human thoracic artery. ${ }^{11)}$ However, we observed sarpogrelate was equally effective in causing vasodilation of cerebral arteries in the absence of 5-HT (Fig. 1). To our knowledge, this is the first study to report sarpogrelate-induced cerebral artery dilation not only in the presence of 5-HT but also in the absence of 5-HT. Moreover, in the present study, the dilatory effects of sarpogrelate were preserved after endothelial denudation or inhibition of nitric oxide synthase, suggesting that the actions of sarpogrelate are independent of vascular endothelium-derived signals.

Platelets contain $5-\mathrm{HT}$, and activation of $5-\mathrm{HT}_{2 \mathrm{~A}}$ receptors by platelet-derived 5-HT has been implicated in platelet aggregation. ${ }^{15)}$ In vitro, ex vivo, and in vivo studies have demonstrated that sarpogrelate acts not only on vascular smooth muscle cells but also on platelets. ${ }^{5)}$ One possibility to explain the sarpogrelate-induced vasodilation which we observed in the absence of exogenous 5-HT would be antagonism of platelet-derived 5-HT. However, in our experimental system, arteries were cannulated and blood flushed from the lumen prior to the initiation of diameter measurements. Thus, the actions of sarpogrelate in the present study were unlikely to reflect antagonism of endogenous platelet-derived 5-HT.

5-HT induced contractions are blocked by L-type calcium channel antagonists such as diltiazem, verapamil, and nifedipine. ${ }^{12,31)} 5-\mathrm{HT}_{2 \mathrm{~A}}$ receptor activation may increase intracellular $\mathrm{Ca}^{2+}$ levels through both release of intracellular stores of $\mathrm{Ca}^{2+}$ and activation of L-type $\mathrm{Ca}^{2+}$ channels. ${ }^{30)}$ In our study, sarpogrelate caused a leftward shift of the concentration-effect curves of calcium channel blockers, the $\mathrm{IC}_{50}$ of diltiazem, verapamil, and nifedipine, without suppressing the maximum response. These findings suggest that sarpogrelate can also act as a competitive antagonist of voltage-dependent calcium channels. Consistent with inhibition of voltagedependent calcium channels by sarpogrelate, we observed that this compound caused a concentration-dependent reversal of pressure-induced myogenic tone in the absence of 5-HT.

Experimentally, inhibition of L-type calcium channels has shown promise in minimizing damage caused by cerebral ischemia. ${ }^{14)}$ However, clinically, most L-type calcium blockers have failed to demonstrate benefits. ${ }^{27)}$ Only nimodipine has been established as a neuroprotectant after subarachnoid hemorrhage. ${ }^{22)}$ In addition, L-type calcium channel blockers have potential therapeutic uses for subcortical vascular dementia ${ }^{19)}$ and Parkinson's disease. ${ }^{23)}$ Thus, as a L-type calcium channel antagonist, sarpogrelate may represent a new and important therapeutic agent in the treatment of cerebral ischemia, subarachnoid hemorrhage, dementia, and Parkinson's disease.

In summary, we report that sarpogrelate abolished cerebral artery constriction in both the absence and presence of exogenous 5-HT. These findings suggest that sarpogrelate acts not only as a $5-\mathrm{HT}_{2 \mathrm{~A}}$ receptor antagonist in smooth muscle cells of rabbit cerebral arteries, but also as a calcium channel blocker. Importantly, voltage-dependent calcium channel blockade may account for the clinical utility of sarpogrelate in the treatment of vascular diseases such as atherosclerosis including diabetes mellitus, Buerger's disease, Raynaud's disease, and coronary artery disease. Furthermore, these findings suggest sarpogrelate may have additional clinical benefits such as acting as a neuroprotectant during cerebral ischemia, dementia, and Parkinson's disease.

\section{Acknowledgments}

This study was supported by Sapporo Medical University Foundation for Promotion of Medical Science, Japan (\#20) and Tanabe-Mitsubishi Chemical Corporation, Tokyo. The authors wish to thank Dr. N. Tohse for helpful comments on this study.

\section{Conflicts of Interest Disclosure}

The authors have no personal financial or institutional interest in any of the drugs, materials, or devices in the article. All authors who are members of The Japan Neurosurgical Society (JNS) have registered online Self-reported COI Disclosure Statement Forms through the website for JNS members.

\section{References}

1) Banes A, Florian JA, Watts SW: Mechanisms of 5hydroxytryptamine (2A) receptor activation of the mitogen-activated protein kinase pathway in vascular smooth muscle. J Pharmacol Exp Ther 291: 1179-1187, 1999

2) de Chaffoy de Courcelles D, Leysen JE, De Clerck F, Van Belle H, Janssen PA: Evidence that phospholipid 
turnover is the signal transducing system coupled to serotonin-S2 receptor sites. J Biol Chem 260: 76037608, 1985

3) Doggrell SA: Sarpogrelate: cardiovascular and renal clinical potential. Expert Opin Investig Drugs 13: 865-874, 2004

4) Fujita M, Minamino T, Sanada S, Asanuma H, Hirata A, Ogita H, Okada K, Tsukamoto O, Takashima S, Tomoike H, Node K, Hori M, Kitakaze M: Selective blockade of serotonin 5-HT2A receptor increases coronary blood flow via augmented cardiac nitric oxide release through 5-HT1B receptor in hypoperfused canine hearts. J Mol Cell Cardiol 37: 1219-1223, 2004

5) Hara H, Osakabe M, Kitajima A, Tamao Y, Kikumoto R: MCI-9042, a new antiplatelet agent is a selective S2-serotonergic receptor antagonist. Thromb Haemost 65: 415-420, 1991

6) Hayashi T, Sumi D, Matsui-Hirai H, Fukatsu A, Arockia Rani PJ, Kano $\mathrm{H}$, Tsunekawa T, Iguchi A: Sarpogrelate $\mathrm{HCl}$, a selective 5-HT2A antagonist, retards the progression of atherosclerosis through a novel mechanism. Atherosclerosis 168: 23-31, 2003

7) Hoyer D, Clarke DE, Fozard JR, Hartig PR, Martin GR, Mylecharane EJ, Saxena PR, Humphrey PP: International Union of Pharmacology classification of receptors for 5-hydroxytryptamine (Serotonin). Pharmacol Rev 46: 157-203, 1994

8) Ichida S, Hayashi T, Terao M: Selective inhibition by ketanserin and spiroperidol of 5-HT-induced myometrial contraction. Eur J Pharmacol 96: 155158,1983

9) Igarashi M, Okuda T, Oh-i T, Koga M. Changes in plasma serotonin concentration and acceleration plethysmograms in patients with Raynaud's phenomenon after long-term treatment with a 5-HT2 receptor antagonist. J Dermatol 27: 643-650, 2000

10) Jassen PAJ: 5-HT2 receptor blockade to study serotonin-induced pathology. Trends Pharmacol Sci 4: 198-206, 1983

11) Kandabashi T, Shimokawa H, Mukai $Y$, Matoba T, Kunihiro I, Morikawa K, Ito M, Takahashi S, Kaibuchi K, Takeshita A: Involvement of rho-kinase in agonists-induced contractions of arteriosclerotic human arteries. Arterioscler Thromb Vasc Biol 22: 243-248, 2002

12) Kass RS, Krafte DS: Electrophysiology of Ca channels in excitable cells; channel types, permeation, gating and modulation, in Venter JC, Triggle D (eds): Structure and Physiology of the Slow Inward Calcium Channel. New York, Alan R Liss, 1987, pp 71-88

13) Kinugawa T, Fujita M, Lee JD, Nakajima H, Hanada $\mathrm{H}$, Miyamoto S: Effectiveness of a novel serotonin blocker, sarpogrelate, for patients with angina pectoris. Am Heart J 144: E1, 2002

14) Kobayashi T, Mori Y: $\mathrm{Ca}^{2+}$ channel antagonist and neuroprotection from cerebral ischemia. Eur J Pharmacol 363: 1-15, 1998

15) Leysen JE, de Chaffoy de Courcelles D, De Clerck F,
Niemegeers CJ, Van Nueten JM: Serotonin-S2 receptor binding sites and functional correlates. Neuropharmacology 23: 1493-1501, 1984

16) Maruyama K, Kinami J, Sugita Y, Takada Y, Sugiyama E, Tsuchihashi H, Nagatomo T: MCI-9042: high affinity for serotonergic receptors as assessed by radioligand binding assay. J Pharmacobiodyn 14: 177-181, 1991

17) Marwood JF: Influence of alpha 1-adrenoceptor antagonism of ketanserin on the nature of its $5-\mathrm{HT}_{2}$ receptor antagonism. Clin Exp Pharmacol Physiol 21: 955-961, 1994

18) Ogawa S, Takeuchi K, Sugimura K, Sato C, Fukuda $\mathrm{M}$, Lee R, Ito S, Sato T: The 5-HT2 receptor antagonist sarpogrelate reduces urinary and plasma levels of thromboxane A2 and urinary albumin excretion in non-insulin-dependent diabetes mellitus patients. Clin Exp Pharmacol Physiol 26: 461-464, 1999

19) Pantoni L, del Ser T, Soglian AG, Amigoni S, Spadari G, Daniela Binelli D, Inzitari D: Efficacy and safety of nimodipine in subcortical vascular dementia. A randomized placebo-controlled trial. Stroke 36: 619-624, 2005

20) Pertz H, Elz S: In-vitro pharmacology of sarpogrelate and the enantiomers of its major metabolite: $5-\mathrm{HT}_{2 \mathrm{~A}}$ receptor specificity, stereoselectivity and modulation of ritanserin-induced depression of 5-HT contractions in rat tail artery. J Pharm Pharmacol 47: 310-316, 1995

21) Pietraszek MH, Takada Y, Taminato A, Yoshimi T, Watanabe I, Takada A: The effect of MCI-9042 on serotonin-induced platelet aggregation in type 2 diabetes mellitus. Thromb Res 70: 131-138, 1993

22) Rinkel GJ, Feigin VL, Algra A, Vermeulen M, van Gijin J: Calcium antagonists for aneurysmal subarachnoid haemorrhage. Cochrane Database Sys Rev (4): CD000277, 2002

23) Ritz B, Rhodes SL, Qian L, Schernhammer E, Olsen JH, Friis S: L-type calcium channel blockers and Parkinson disease in Denmark. Ann Neurol 67: 600-606, 2010

24) Rydzewski A, Urano T, Hachiya T, Kaneko H, Baba S, Takada Y, Takada A: The effect of a $5 \mathrm{HT} 2$ receptor antagonist sarpogrelate (MCI-9042) treatment on platelet function in Buerger's disease. Thromb Res 84: 445-452, 1996

25) Satomura K, Takase B, Hamabe A, Ashida K, Hosaka H, Ohsuzu F, Kurita A. Sarpogrelate, a specific 5HT2-receptor antagonist, improves the coronary microcirculation in coronary artery disease. Clin Cardiol 25: 28-32, 2002

26) Schoeffter P, Hoyer D: 5-Hydroxytryptamine (5-HT)induced endothelium-dependent relaxation of pig coronary arteries is mediated by 5 -HT receptors similar to the $5-\mathrm{HT}_{1 \mathrm{D}}$ receptor subtype. J Pharmacol Exp Ther 252: 387-395, 1990

27) Trust Study Group: Randomised, double-blind, placebo-controlled trial of nimodipine in acute stroke. 
Lancet 336: 1205-1209, 1990

28) Tsuchihashi H, Yagi N, Kimura M, Shirota K, Kinami J, Nagatomo T: Binding characteristics of [3H]ketanserin for serotonin-2 receptor in the rabbit platelet. J Pharmacobiodyn 14: 461-466, 1991

29) Villalón CM, Centurión D: Cardiovascular responses produced by 5-hydroxytriptamine: a pharmacological update on the receptors/mechanisms involved and therapeutic implications. Naunyn Schmiedebergs Arch Pharmacol 376: 45-63, 2007

30) Watts SW: Activation of the mitogen-activated protein kinase pathway via the $5-\mathrm{HT}_{2 \mathrm{~A}}$ receptor. Ann NY Acad Sci 861: 162-168, 1998

31) Wendling WW, Harakal C: Effects of calcium antagonists on isolated bovine cerebral arteries: inhibi- tion of constriction and calcium-45 uptake induced by potassium or serotonin. Stroke 18: 591-598, 1987

32) WHO Collaborating Centre for Drug Statistics Methodology: ATC/DDC Index. Available at http:// www.whocc.no/atc _ ddd _ index/?code = C02KD01. Accessed September 30, 2011

Address reprint requests to: Masanori Ishiguro, $\mathrm{MD}, \mathrm{PhD}$, Department of Systems Neuroscience, School of Medicine, Sapporo Medical University, S1W17, Chuo-ku, Sapporo 060-8556, Japan.

e-mail: ishiguro@sapmed.ac.jp 